\title{
lodide uptake by negatively charged clay interlayers?
}

\author{
Andrew Miller ${ }^{1,{ }^{*}}$, Jessica Kruichak ${ }^{2}$, Melissa Mills ${ }^{2}$, Yifeng Wang ${ }^{2}$ \\ ${ }^{1} 1$ Kellogg Circle, Emporia State University, Emporia, KS, United States, 66801 \\ ${ }^{2} 1515$ Eubank SE, Sandia National Laboratories, Albuquerque, NM, United States, 87185-0779 \\ ${ }^{*}$ Corresponding author:
}

Phone: 620.341 .5988

e-mail: andrew.walker.miller@gmail.com 


\begin{abstract}
Understanding iodide interactions with clay minerals is critical to quantifying risk associated with nuclear waste disposal. Current thought assumes that iodide does not interact directly with clay minerals due to electrical repulsion between the iodide and the negatively charged clay layers. However, a growing body of work indicates a weak interaction between iodide and clays. The goal of this contribution is to report a conceptual model for iodide interaction with clays by considering clay mineral structures and emergent behaviors of chemical species in confined spaces. To approach the problem, a suite of clay minerals was used with varying degrees of isomorphic substitution, chemical composition, and mineral structure. lodide uptake experiments were completed with each of these minerals in a range of swamping electrolyte identities $(\mathrm{NaCl}, \mathrm{NaBr}, \mathrm{KCl})$ and concentrations. lodide uptake behaviors form distinct trends with cation exchange capacity and mineral structure. These trends change substantially with electrolyte composition and concentration, but do not appear to be affected by solution $\mathrm{pH}$. The experimental results suggest that iodide may directly interact with clays by forming ionpairs (e.g., $\mathrm{Nal}_{(\mathrm{aq})}$ ) which may concentrate within the interlayer space as well as the thin areas surrounding the clay particle where water behavior is more structured relative to bulk water. Ion pairing and iodide concentration in these zones is probably driven by the reduced dielectric constant of water in confined space and by the relatively high polarizability of the iodide species.
\end{abstract}

Keywords: nuclear waste, radioiodine, ion pairing, clay minerals

\title{
1. Introduction
}

Subsurface clay formations are one of the major rock types being considered by several countries for geologic disposal of nuclear waste. Even when clays will not be used as host rock, engineered barrier materials often include a compacted bentonite buffer surrounding a waste package for chemical and structural stabilization. Clays are an ideal material as they possess low permeabilities where ion transport is dominated by diffusion. Clays also possess high sorption capacities for many cations present in nuclear waste. The high cationic sorption capacities are caused by the simultaneous presence of negatively charged cation exchange sites on the planar surfaces of clay layers, and amphoteric surface complexation sites on the edge of the layer. However, the negative structural charge minimizes anion interactions with clays. lodine is expected to be present as iodide under the reducing conditions of waste disposal in clay (Whitehead, 1984). The assumed lack of interaction between iodide and clays causes iodine-129 to have earlier breakthrough times and make a larger contribution to predicted dose from a deep geological repository compared to other radionuclides (Altmann, 2008, Mallants et al., 2001). Performance assessment calculations show that even a small retention capability of clay materials for iodide can make a substantial difference in total dose predictions (Altmann, 2008).

A growing body of work points to the potential presence of a weak interaction between iodide and clays (Bazer-Bachi et al., 2006, Jansson and Eriksen, 2004, Van Loon et al., 2003) (Descostes et al., 2008, Wittebroodt et al., 2008, Savoye et al., 2012). The weakness of the interaction has made experimental measurements somewhat contradictory. Several major hypotheses exist to explain observed interactions, including: isotopic dilution with native iodine (Tournassat et al., 2007, Gaucher et 
al., 2004), co-precipitation or uptake into carbonates (Claret et al., 2010, Montavon et al., 2014), the presence of organic matter (Fuge and Johnson, 1986, Hu and Moran, 2005, Kaplan, 2003, Li et al., 2014), uptake to ancillary minerals (Couture and Seitz, 1983, Fuhrmann et al., 1998), and impure radiotracers or unconsidered alterations to iodide redox state (Glaus et al., 2008, Tournassat et al., 2007, Hu et al., 2005). All of these explanations rely on the premise that iodide does not interact with clays in any meaningful way, and the observed iodide uptake and retardation are caused by other components or processes occurring in natural clay samples.

Attempts to gain a mechanistic understanding of iodide interaction with clays and clay bearing soils are rare. In two separate studies iodide uptake tends to increase with decreasing $\mathrm{pH}$ both for pure illite and a natural soil sample (Kaplan, 2003, Kaplan et al., 2000). This is consistent with an outer sphere interaction with highly protonated, positively charged metal oxides and clay edge sites. However, most diffusion studies and porewater analysis from clay mineral systems have $\mathrm{pH}$ values $>7$ (Gaucher et al., 2006) limiting this mechanism in natural systems. As pointed out by others (Tournassat et al., 2007), if edge complexation was controlling iodide behaviors similar responses would be expected between clays with similar edge charge behavior such as illite and montmorillonite. But illite has been shown to have much higher uptake than montmorillonite (Kaplan et al., 2000).

The goal of this study is to consider interactions between iodide and clays beyond those described in classical interpretations of clay surface chemistry (Bradbury and Baeyens, 1997, Baeyens and Bradbury, 1997). This new view requires a different experimental approach. Most studies examining iodide interactions with clay minerals use clay samples from a specific formation of interest to a national nuclear waste disposal program, or on purified clay minerals generically relevant to waste disposal, most commonly montmorillonite and illite. The focus on these clays and clay minerals is pragmatic and directly useful; however, it limits data interpretation within the confines of classical clay surface chemistry models and/or with $\mathrm{K}_{\mathrm{D}}$ values. Single clay studies remove the ability to compare uptake as a function of other key clay characteristics, including: structural charge variability, different layer structures, and variable nanopore scale chemistry caused by constrained space within the clay mineral (Miller and Wang, 2012). In this study, we focus on a series of clay minerals, and measure iodide uptake under several swamping electrolyte strengths and compositions. lodide uptake is reported as a function of lattice substitution (represented by the cation exchange capacity value, CEC) and as a function of clay structure. Two classes of clay structure are used in these experiments, layered and fibrous clays. The results imply a mechanism including ion-pair formation and the concentration of iodide within the interlayers and other confined pore spaces.

\section{Materials and Methods}

\subsection{CEC and surface area determinations}

The surface areas and CEC of the clay minerals were measured using $\mathrm{N}_{2}$ BET (Brunauer et al., 1938), methylene blue exchange, and $\mathrm{BaCl}_{2}$ exchange. Nitrogen ( $\mathrm{N}_{2}$ gas) is generally considered unable to enter the interlayer porosity and only represents the external surface area of clays. Methylene blue adsorption takes place in aqueous solution where the clays can de-laminate giving both a total surface area. The methylene blue (MB) procedure requires sodium exchanged clays (Kahr and Madsen, 1995). 
The clays were converted to the sodium form using a method similar to the gentle purification method in (Bergaya et al., 2006). The clays were mixed with a $1.0 \mathrm{M} \mathrm{NaCl}$ solution overnight. For all of the clays except montmorillonite, a single centrifugation for 60 minutes at $4400 \mathrm{~g}$ was sufficient to separate the clay from the solution. The montmorillonite often required several centrifuge cycles (6-7 hours). Once a pellet was formed, the solution was decanted and discarded, and fresh $\mathrm{NaCl}$ solution was added. The mixing and centrifugation processes were repeated three times. The entire process was repeated three times with $\mathrm{DI}$ water instead of $1.0 \mathrm{M} \mathrm{NaCl}$. Once the clays were washed they were dried in a $100^{\circ} \mathrm{C}$ oven for several days before the MB determination was completed. The MB surface area determination uses a fixed solid:liquid ratio $(20 \mathrm{~g} / \mathrm{L})$ and an increasing concentration of $\mathrm{MB}$. Sorption isotherms are plotted, and the surface is assumed to be saturated at the point where the isotherm shifts from being linear (Kahr and Madsen, 1995). The total amount of MB exchanged can then be calculated. Barium exchange also takes place in aqueous solution. Barium is added in excess ( $0.1 \mathrm{M}$ solution) to a clay slurry (solid:solution $=6.25 \mathrm{~g} / \mathrm{L}$ ) thereby displacing all of the native cations. Major cations ( $\mathrm{Na}, \mathrm{Ca}, \mathrm{K}, \mathrm{Mg}, \mathrm{Fe}$ ) can then be measured and the exchange capacity determined (Gillman, 1979). The major cations were measured by inductively coupled plasma-optical emission spectroscopy (ICP-OES).

\subsection{Clay minerals and purification}

The clays used all originate from the Clay Mineral Society source clays project at Purdue University. Seven total clays were used including: kaolinite, ripidolite, illite, montmorillonite, palygorskite, sepiolite, and a 70/30 illite/smectite mixed layer (ID numbers: KGa-1b, CCa-2, IMt-1, SWy2, PFI-1, SepNev-1, and ISCz-1, respectively). The layered clays are kaolinite, ripidolite, illite, montmorillonite and the illite/smectite mixed layer. The fibrous clays are palygorskite and sepiolite. All of the clay minerals were subjected to dry sieving at 75 microns. The $<75$ micron fraction was used in all the experiments presented here. Each clay was examined by X-ray diffraction (XRD) analysis for impurities. The kaolinite, sepiolite, and ripidolite did not have any measurable impurity minerals. All of the other clays had measurable amounts of quartz. There were no other clearly identifiable oxides or carbonates. The best match to the illite spectrum was muscovite, although due to the small degree of crystallinity, the spectra peaks were small. The XRD spectra for the illite/smectite mixed layer clay most closely resembled pure illite, although the match was not exact. Initial surface titrations showed significant $\mathrm{pH}$ buffering around $\mathrm{pH} 8.3$, suggesting a calcite impurity in the illite and montmorillonite samples that was not detectable using XRD. The buffering capacity was non-existent in samples subjected to the Na-exchange procedure described above. For the iodide uptake experiments, the $<75$ micron fraction was used without further purification.

\section{3 lodide sorption experiments}

Batch iodide sorption experiments were completed in at least triplicate for all of the clay minerals. For each set of experiments, the ionic composition and concentration of the swamping electrolyte was held constant. The electrolytes and concentrations used are shown in Table 1. A constant solid:solution ratio of $100 \mathrm{~g} / \mathrm{L}$ was used in all of the experiments. 
Table 1- Summary of electrolytes and concentrations for batch uptake experiments. An $\times$ denotes which were used in these experiments.

\begin{tabular}{cccc}
\hline Concentration (M) & $\mathrm{NaCl}$ & $\mathrm{NaBr}$ & $\mathrm{KCl}$ \\
\hline 1.0 & $\times$ & & \\
0.1 & $\times$ & $\times$ & $\times$ \\
0.01 & $\times$ & & \\
\hline
\end{tabular}

The batch reactors were $50 \mathrm{~mL}$ centrifuge tubes. Blanks (electrolyte and iodide spike without clay) confirmed the absence of wall sorption or iodide loss to volatilization. Clay blanks (electrolyte and clay without iodide) confirmed the lack of leachable iodide from the clays. To each tube the clay and electrolyte solution was added, and the suspensions were equilibrated overnight. An iodide spike was added after equilibration. A constant iodide concentration of $3.94 \mathrm{E}-4 \mathrm{M}(50 \mathrm{mg} / \mathrm{L})$ was used for all of the batch reactors. The spike was an ion chromatography (IC) iodide standard with no detectable iodate. The batch reactors were mixed in the dark at room temperature for 7 days in a horizontal position on a shaker table. After 7 days, the samples were centrifuged for 1 hour at $4400 \mathrm{~g}$. The supernatant was removed with a pipette and refrigerated for analysis. The $\mathrm{pH}$ was measured immediately before the iodide spike was added, and again at the end of the 7 day mixing period both before and after centrifuging. No attempt was made to keep the $\mathrm{pH}$ constant or at a specific level. As mentioned above, the $\mathrm{pH}$ in the illite and montmorillonite reactors was controlled both by the clay and potentially through some amount of calcite dissolution. For all of the other clays, the $\mathrm{pH}$ was controlled only through clay buffering. The $\mathrm{pH}$ reported is the equilibrium $\mathrm{pH}$ for the given clay minerals in the specified electrolyte. After the uptake sample had been removed, an equal amount of DI water was added to the vial. The slurry was mixed for four days. At the end of four days the sample was centrifuged as above, and a sample was removed for analysis. This sample represents a reversal of the uptake process, and gives information regarding the oxidation state of the iodine species after uptake.

The samples were analyzed using a Dionex 1100 ion chromatograph (IC) with an AS23 guard and analytical column, and a bicarbonate/carbonate eluent. For the eluent and column used both iodate and iodide were observable.

\section{Results}

\subsection{CEC and surface area}

Table 2 shows the results of the CEC and surface area determinations. CEC values are generally in good agreement, approximately within a factor of 2 to published values for the source clays (Borden and Giese, 2001). Methylene blue sorption allows for the calculation of surface area assuming monolayer sorption and a molecular area of $130 \AA^{2}$. Generally methylene blue surface areas are higher than BET surface area determinations. The BET surface area is interpreted as representing only the 
external surface area of the clay particles; the methylene blue surface area is more representative of the total surface area. The difference between them is the interlayer area. Sepiolite is the one exception to the general behavior. The BET surface area was larger than the methylene blue surface area, possibly due to $\mathrm{N}_{2}$ condensation within the nanochannels of the material (Cases et al., 1991). This leads to the physically meaningless negative internal surface area shown in Table 2.

Table 2- CEC and surface area values for the clays used. Surface area determination methods are explained in the text.

\begin{tabular}{lcccc}
\hline & $\begin{array}{c}\mathrm{BaCl}_{2} \mathrm{CEC} \\
(\mathrm{meq} / 100 \mathrm{~g})\end{array}$ & $\begin{array}{c}\text { BET S.A. } \\
\left(\mathrm{m}^{2} / \mathrm{g}\right)\end{array}$ & $\begin{array}{c}\text { MB S.A. } \\
\left(\mathrm{m}^{2} / \mathrm{g}\right)\end{array}$ & $\begin{array}{c}\text { Internal S.A. } \\
\left(\mathrm{m}^{2} / \mathrm{g}\right)\end{array}$ \\
\hline Kaolinite & 4.61 & 11.3 & 11.8 & 0.45 \\
Ripidolite & 6.03 & 8.02 & 23.5 & 15.5 \\
Illite & 27.6 & 31.5 & 117 & 85.8 \\
Illite/Smectite & 30.4 & 29.8 & 193 & 163 \\
Montmorillonite & 152 & 28.3 & 857 & 829 \\
Sepiolite & 8.98 & 201 & 136 & -65.2 \\
Palygorskite & 29.2 & 142 & 625 & 484 \\
\hline
\end{tabular}

\section{2 lodide batch uptake experiments}

Table 3 shows the initial and final $\mathrm{pH}$ values in the experiments. In general the values are somewhat bimodal being centered around $\mathrm{pH} 4$ or $\mathrm{pH} 8$. During the course of mixing, the $\mathrm{pH}$ changed only slightly, typically decreasing within $\sim 0.2 \mathrm{pH}$ units. Centrifuging caused larger shifts in $\mathrm{pH}$, the largest being $0.98 \mathrm{pH}$ units for the $\mathrm{KCl}$ electrolyte experiments with ripidolite (data not shown). Differences between equimolar electrolytes are fairly small suggesting similar $\mathrm{Na}^{+} / \mathrm{H}^{+}$and $\mathrm{K}^{+} / \mathrm{H}^{+}$exchange constants. With increasing sodium concentration, the $\mathrm{pH}$ decreases consistent with $\mathrm{Na}^{+}$exchange for $\mathrm{H}^{+}$on the basal surfaces of the clays.

Solid:liquid partitioning coefficients ( $K_{D}$ values, $\mathrm{mL} / \mathrm{g}$ ) were calculated using equation 1 ,

$$
K_{D}=\frac{\left(C_{I}-C_{F}\right)}{C_{F} * S}
$$

where $C_{I}$ is the initial aqueous iodide concentration $(\mathrm{mg} / \mathrm{L}), C_{F}$ is the final aqueous iodide concentration $(\mathrm{mg} / \mathrm{L})$, and $\mathrm{S}$ is the solid:solution ratio $(\mathrm{g} / \mathrm{mL})$. Table 4 shows iodide $K_{D}$ values as a function of electrolyte identity, and Table 5 shows iodide $\mathrm{K}_{\mathrm{D}}$ values as a function of $\mathrm{NaCl}$ concentration. Negative values are generally interpreted to be anion exclusion due to the fixed negative charge of the clay interface. The correction of iodide uptake for this anion exclusion effect is difficult due to the inability to quantify the liquid volume affected by anion exclusion. The $K_{D}$ values presented here can thus be viewed as a lower bound for iodide uptake. As with other studies, the error (standard deviation of at least three replicates) 
is often the same magnitude or larger than the $K_{D}$ value. In this case, the arithmetic standard deviation is used only to gauge experimental variability. Instead of considering the values themselves, trends between the clays under the different electrolyte conditions are of interest. For the layered clays, $\mathrm{K}_{\mathrm{D}}$ values are correlated with the total surface area of the clay minerals for both $\mathrm{NaCl}$ and $\mathrm{KCl}$ electrolytes (Figure 1). Since the total surface area is dominated by the internal surface area, similar relationships are found with internal surface area or CEC. No obvious trends are found when uptake is plotted as a function of external surface area (see Supporting Information). The nature of the trends is influenced by swamping electrolyte compositions, but they are essentially independent of $\mathrm{pH}$ (Table 3). For example, the iodide uptake trend with $\mathrm{NaCl}$ declines with increasing total surface area, while the uptake trend with $\mathrm{NaBr}$ is quite flat. In both the $\mathrm{NaCl}$ and $\mathrm{NaBr}$ experiments the $\mathrm{pH}$ values are similar. For experiments with variable concentrations of $\mathrm{NaCl}$, the uptake trends are similar in nature for both the $0.01 \mathrm{M}$ and $0.1 \mathrm{M} \mathrm{NaCl}$; uptake decreases with increasing total surface area (Figure 2). Also, the uptake is larger with $0.1 \mathrm{M} \mathrm{NaCl}$ concentrations than with $0.01 \mathrm{M}$. At the $1.0 \mathrm{M} \mathrm{NaCl}$ concentration, the trend is dramatically different with positive $K_{D}$ values for all of the layered clays, and a very slight increase with increasing surface area. The fibrous clays (palygorskite and sepiolite) act substantially different than the layered clays. For four out of the five electrolyte identities and concentrations, the $K_{D}$ value increases with CEC; the one exception is at $0.01 \mathrm{M} \mathrm{NaCl}$.

While iodide was quantified using the IC technique, iodate quantitation was hampered by an impurity present in many of the clays which could not be resolved from iodate. However, the unresolved peak areas in the iodide uptake samples were no larger than peak areas from the clay blanks suggesting no conversion of iodide to iodate. Further, in the water rinses performed after the iodide uptake experiments, iodide was present and quantifiable. The impurity peak areas were again no larger than those from clay blanks treated in an identical manner. The amount of iodide associated with the clays was an insignificant fraction of the total mass added, invalidating attempts to use mass balance calculations to determine iodide to iodate conversions. These results suggest that all of the uptake behaviors presented are iodide interactions with clay minerals, and there was little to no conversion to iodate.

\section{Discussion}

In developing a conceptual model for iodide uptake in these experiments two major factors need to be considered. The first is the $K_{D}$ relationship as a function of electrolyte composition. If an anion exchange type of mechanism were controlling iodide behavior, similar results would be expected for equimolar $\mathrm{Cl}^{-}$concentrations. Since the $\mathrm{NaCl}$ and $\mathrm{KCl}$ experiment showed very different results anion exchange can be ruled out, corroborating the mathematical analysis rejecting non-specific anion exchange in (Tournassat et al., 2007). If the interaction were based solely on surface charge properties and the nature of the electrical double layer, similar results would be expected between the $\mathrm{NaCl}$ and $\mathrm{NaBr}$ experiments. With the $\mathrm{Na}^{+}$ion being present in equimolar concentrations, the interlayer spacing for a given clay should be identical as should the surface charge distribution into solution. However, the 
Table 3- Initial (before the iodide spike was added) and final (after the centrifugation) pH values for the various electrolytes and electrolyte concentrations used.

\begin{tabular}{|c|c|c|c|c|c|c|c|c|c|c|}
\hline & \multicolumn{6}{|c|}{$0.1 \mathrm{M}$ Electrolyte } & \multicolumn{4}{|c|}{$\mathrm{NaCl}$ Electrolyte } \\
\hline & \multicolumn{2}{|c|}{$\mathrm{NaCl}$} & \multicolumn{2}{|c|}{$\mathrm{NaBr}$} & \multicolumn{2}{|c|}{$\mathrm{KCl}$} & \multicolumn{2}{|c|}{$0.01 \mathrm{M}$} & \multicolumn{2}{|c|}{$1.0 \mathrm{M}$} \\
\hline & $\begin{array}{c}\text { Initial } \\
\mathrm{pH}\end{array}$ & $\begin{array}{c}\text { Final } \\
\mathrm{pH}\end{array}$ & $\begin{array}{c}\text { Initial } \\
\mathrm{pH}\end{array}$ & $\begin{array}{c}\text { Final } \\
\mathrm{pH}\end{array}$ & $\begin{array}{c}\text { Initial } \\
\mathrm{pH}\end{array}$ & $\begin{array}{c}\text { Final } \\
\mathrm{pH}\end{array}$ & $\begin{array}{c}\text { Initial } \\
\mathrm{pH}\end{array}$ & $\begin{array}{c}\text { Final } \\
\mathrm{pH}\end{array}$ & $\begin{array}{c}\text { Initial } \\
\mathrm{pH}\end{array}$ & $\begin{array}{c}\text { Final } \\
\mathrm{pH}\end{array}$ \\
\hline Kaolinite & 4.23 & 4.39 & 4.43 & 4.28 & 4.18 & 4.07 & 4.70 & 4.73 & 4.27 & 4.19 \\
\hline Ripidolite & 8.73 & 8.10 & 8.76 & 8.20 & 8.79 & 7.81 & 8.79 & 8.15 & 8.59 & 8.37 \\
\hline Illite & 8.45 & 8.16 & 8.48 & 7.95 & 8.28 & 8.01 & 8.68 & 8.30 & 8.22 & 7.87 \\
\hline Illite/Smectite & 4.00 & 4.24 & 4.22 & 4.03 & 3.91 & 3.82 & 4.38 & 4.40 & 3.65 & 3.74 \\
\hline Montmorillonite & 8.15 & 8.05 & 8.19 & 8.05 & 8.09 & 7.90 & 8.65 & 8.50 & 7.77 & 7.73 \\
\hline Sepiolite & 7.89 & 7.83 & 7.98 & 7.75 & 7.92 & 7.80 & 7.92 & 7.83 & 7.50 & 7.71 \\
\hline Palygorskite & 7.98 & 7.90 & 8.05 & 7.82 & 7.84 & 7.87 & 8.17 & 7.99 & 7.75 & 7.75 \\
\hline
\end{tabular}


Table 4- $K_{D}$ values for iodide in the different swamping electrolytes used. Standard deviation is presented in parentheses.

\begin{tabular}{|c|c|c|c|c|}
\hline \multicolumn{5}{|c|}{$0.1 \mathrm{M}$ Electrolyte } \\
\hline & \multirow{2}{*}{$\frac{\mathrm{BaCl}_{2} \mathrm{CEC}}{\mathrm{meq} / 100 \mathrm{~g}}$} & \multicolumn{3}{|c|}{$K_{D}[\mathrm{~mL} / \mathrm{g}]$ (Std. Dev.) } \\
\hline & & $\underline{\mathrm{NaCl}}$ & $\mathrm{NaBr}$ & $\underline{\mathrm{KCl}}$ \\
\hline Kaolinite & 4.61 & $1.61(0.28)$ & $0.02(0.63)$ & $-0.01(0.22)$ \\
\hline Ripidolite & 6.03 & $1.13(0.38)$ & $-0.16(0.72)$ & $-0.31(0.17)$ \\
\hline Illite & 27.6 & $0.54(0.12)$ & $0.13(0.002)$ & $-0.50(0.24)$ \\
\hline Illite.Smectite & 30.4 & $0.38(0.08)$ & $-0.01(0.11)$ & $-0.49(0.11)$ \\
\hline Montmorillonite & 152 & $-0.32(0.35)$ & $-0.58(0.07)$ & $-1.69(0.90)$ \\
\hline Sepiolite & 8.98 & $0.01(0.28)$ & $0.79(0.14)$ & $0.11(0.30)$ \\
\hline Palygorskite & 29.2 & $0.24(0.30)$ & $1.26(0.05)$ & $0.99(0.17)$ \\
\hline
\end{tabular}

Table 5- $\mathrm{K}_{\mathrm{D}}$ values for iodide in variable concentrations of $\mathrm{NaCl}$ electrolyte. Standard deviation is presented in parentheses.

\begin{tabular}{|c|c|c|c|c|}
\hline \multicolumn{5}{|c|}{$\mathrm{NaCl}$ Electrolyte } \\
\hline & \multirow{2}{*}{$\begin{array}{l}\mathrm{BaCl}_{2} \mathrm{CEC} \\
\mathrm{meq} / 100 \mathrm{~g}\end{array}$} & \multicolumn{3}{|c|}{$\mathrm{K}_{\mathrm{D}}[\mathrm{mL} / \mathrm{g}]$ (Std. Dev) } \\
\hline & & $\underline{0.01 \mathrm{M}}$ & $\underline{0.1 \mathrm{M}}$ & $\underline{1.0 \mathrm{M}}$ \\
\hline Kaolinite & 4.61 & $0.48(0.26)$ & $1.61(0.28)$ & $0.11(0.29)$ \\
\hline Ripidolite & 6.03 & $0.14(0.21)$ & $1.13(0.38)$ & $0.44(0.17)$ \\
\hline Illite & 27.6 & $-0.46(0.41)$ & $0.54(0.12)$ & $0.27(0.21)$ \\
\hline Illite.Smectite & 30.4 & $-0.16(0.25)$ & $0.38(0.08)$ & $0.30(0.08)$ \\
\hline Montmorillonite & 152 & $-1.35(0.54)$ & $-0.32(0.35)$ & $0.60(0.09)$ \\
\hline Sepiolite & 8.98 & $1.38(4.03)$ & $0.01(0.28)$ & $-0.01(0.30)$ \\
\hline Palygorskite & 29.2 & $-0.23(0.54)$ & $0.24(0.30)$ & $0.70(0.26)$ \\
\hline
\end{tabular}




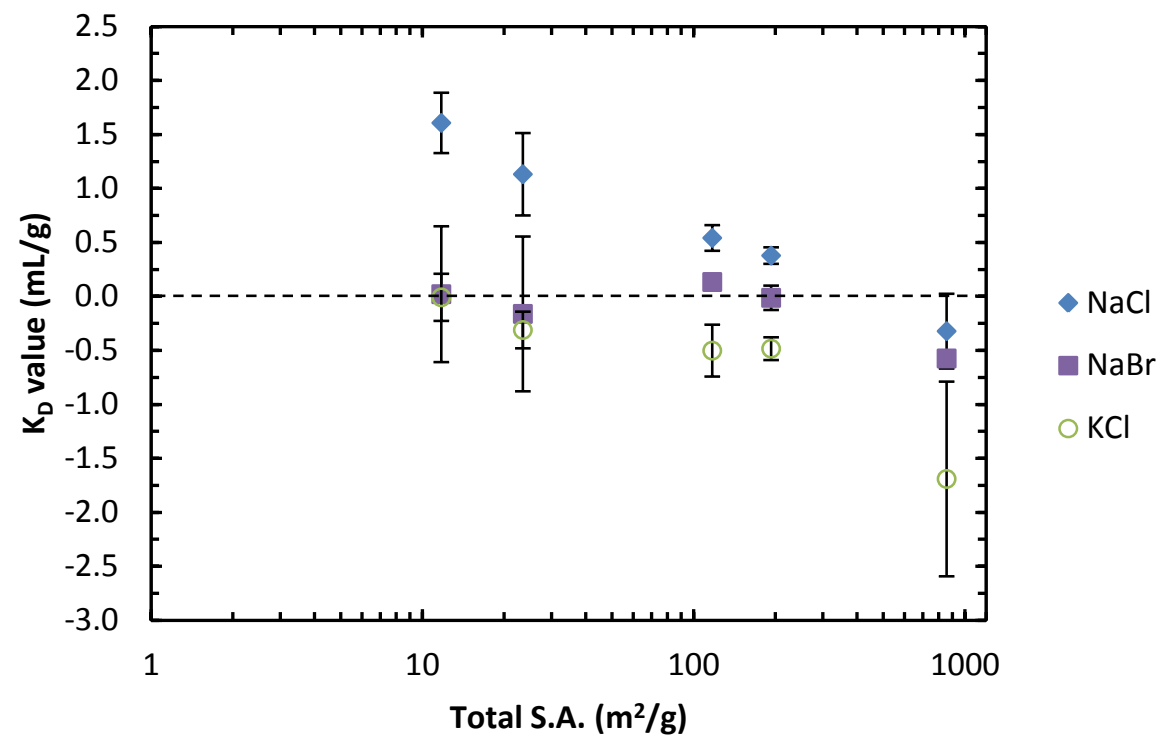

Figure 1- $K_{D}$ values for the layered clays as a function of the total surface area for the three electrolytes considered.

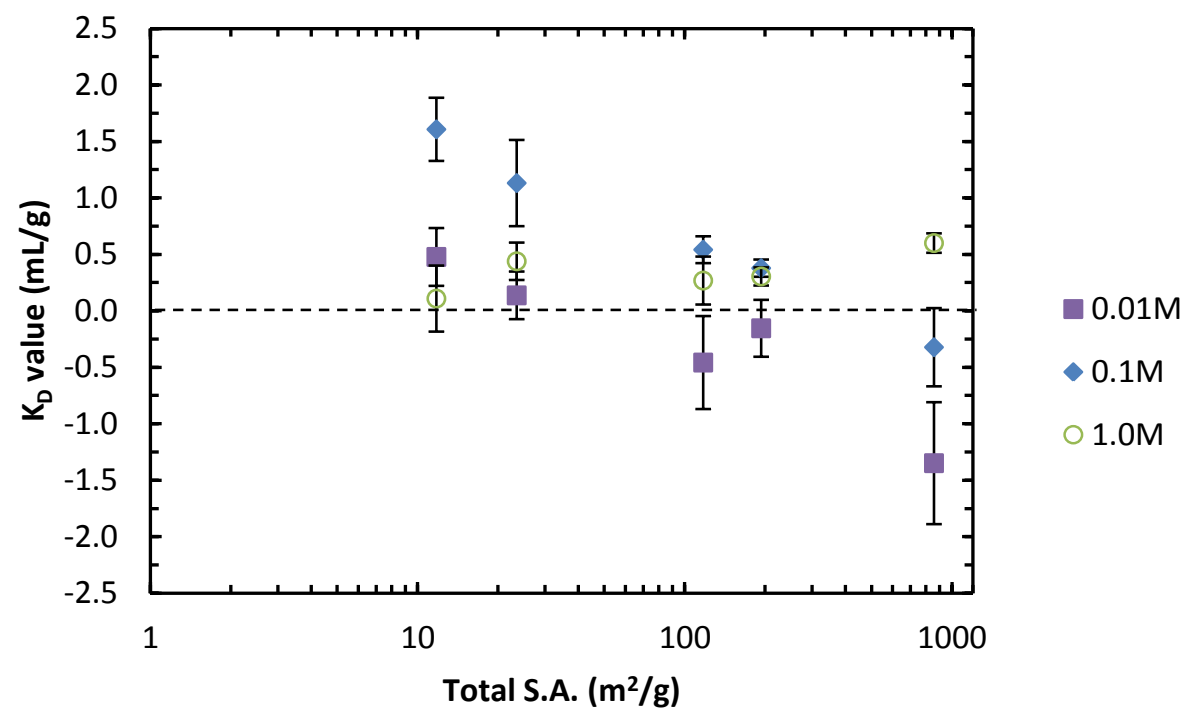

Figure 2- $K_{D}$ values for the layered clays as a function of total surface area for each of the $\mathrm{NaCl}$ concentrations used. 
iodide did not behave similarly in these two systems either. The underlying mechanism is dependent both on the cation and anion present in the swamping electrolyte. The second major consideration is the physical location of iodide. The trend between $K_{D}$ and CEC with total surface area (Figures 1 and 2) and lack of trend with BET surface area (Supporting Information) suggest iodide interactions with negatively charged sites in the clay interlayers. This is supported by the facts that the observed trend is not related to solution $\mathrm{pH}$ (Table 3 ) and that there is no obvious trend between $\mathrm{K}_{\mathrm{d}}$ and external surface area (Supporting Information), both indicating that external surface sites (i.e., edge sites) do not play a significant role in iodide uptake by clay materials for the conditions considered here. Using classical clay models, iodide cannot approach areas of negative charge due to electrical repulsion. This suggests the iodide is not present as free iodide, but instead as a neutral or positively charged species. Ion-pairing and subsequent interaction with the clays is a potential mechanism consistent with the data. It has also been suggested as a possible mechanism in clay diffusion studies (Appelo et al., 2010) (Kozaki et al., 2001) and has been studied as a process for a significant period of time (Sposito, 1991, Mattigod et al., 1985, Sposito et al., 1983) (Charlet and Tournassat, 2005). Previous work predominantly focuses on a monovalent anion association with a polyvalent cation yielding an aqueous species with an overall positive charge (e.g., $\mathrm{CaCl}^{+}$and $\mathrm{CaB}(\mathrm{OH})_{4}^{+}$). However, in this case the expected ion-pairs are neutral (e.g., $\mathrm{Nal}_{(\mathrm{aq})}$ ), which removes the thermodynamic driving force of positively charged ion-pair association with the negatively charged clay surface.

To gain a driving force for the neutral ion-pair to concentrate in the zone of negative charge on the clay surfaces, relative hydration energies and polarizbility of the anions may need to be invoked. Within 1-2 water layers surrounding a mineral phase, water properties are heavily affected by the mineral surface and are distinctly different from those in bulk solution (Hiemstra and Van Riemsdijk, 1991). For most minerals in dilute systems this effect is negligible. However for clays, the large specific surface area and interlayer environments may create a significant amount of confined volume where water properties are different from bulk solution. Most notably, the confined structure decreases the dielectric constant in both charged and uncharged pores (Senapati and Chandra, 2001, Yeh and Berkowitz, 1999). Ion pair formation is increasingly favored as the dielectric constant decreases (Fuoss, 1980 , Shock and Helgeson, 1988). Thus within the confined spaces of the clay interlayer, free iodide is less likely than in bulk solution. Furthermore, at air-water and hydrophobic surface-water interfaces, a similar change to water structure and dielectric is expected. Within about $2 \mathrm{~nm}$ of the interface, halogen concentrations follow the Hofmeister series, $\mathrm{F}<\mathrm{Cl}<\mathrm{Br}<\mathrm{l}$. Bromide and iodide concentrations are larger at the interface than in bulk, chloride is approximately equally distributed, and fluoride concentrations are smaller at the interface than in bulk solution (Figure 3a) (Jungwirth and Tobias, 2001, Lima et al., 2008, Manciu and Ruckenstein, 2005). This trend is explained by comparing the relative polarizability of the anions. It is more thermodynamically favored for the highly polarizable iodide to be present in areas where water is more structured. In equimolar halogen solutions, the relative concentrations are also a function of surface charge (Lima et al., 2008). The data presented here are generally consistent with the work completed for other types of surfaces. Bromide and iodide have more similar polarizabilities than chloride and iodide. When shifting from a $\mathrm{NaCl}$ to a $\mathrm{NaBr}$ electrolyte, the $\mathrm{Br}$ competes more directly with iodide uptake mechanisms, and the relatively higher concentration of $\mathrm{Br}$ can displace iodide leading to smaller iodide $K_{D}$ values. Chloride is less likely to displace iodide as it is significantly less polarizable than iodide, and the iodide $K_{D}$ values are higher. This conceptual model is also consistent with (Kaplan et al., 
2000) who found increased iodide desorption efficiency when mixed with equimolar salt solutions in the order $\mathrm{F}<\mathrm{Cl}<\mathrm{Br}<\mathrm{l}$. Also, the larger iodide uptake in $\mathrm{Na}$ dominated systems compared to the $\mathrm{K}$ systems for the layered clays is consistent with the trend in ion pair formation constants (Fuoss, 1980). Considering the role of structured water in a confined space favorably compares with the data as the electrolyte identity changes, and it may also explain the difference in iodide behavior between the clay structures. The channel structure of the fibrous clays is considerably different from the platy structure of the layered clays and so is iodide uptake. Palygorskite and illite have similar CEC values, and yet the iodide uptake as a function of electrolyte concentration and identity is significantly different. When moving from the $\mathrm{NaCl}$ to either the $\mathrm{NaBr}$ or $\mathrm{KCl}$ electrolyte uptake decreases in illite while increasing with palygorskite. Furthermore, comparing uptake between palygorskite and sepiolite, the expectation based on charge exclusion is less iodide uptake for the more highly negatively charged palygorskite. And yet uptake is almost always higher with palygorskite than it is with sepiolite. This conformational difference between the fibrous and layered clays and the different sizes of the pore channels between the fibrous clays may lead to variable water properties leading to increased uptake despite the higher structural charge (Ockwig et al., 2009, Galan, 1996).

Current mathematical interpretations of the changing dielectric constant describe the dielectric as a function of distance away from the interface (Manciu and Ruckenstein, 2005) (Lima et al., 2008). These models use interconnected partial differential equations, which may or may not be informed/simplified by molecular dynamics calculations. Clays are simpler in that a 2-box model may be sufficient; one box represents the bulk water and the other box represents the confined water (Figure 3B). However, calculating the dielectric constant in the interlayer is not trivial. The exact interlayer spacing depends on the structural charge of the clay as well as the exchanging ion (Laird, 2006). The dielectric constant will depend on both the spacing and the geometry of the interlayer (layered vs. fibrous). The 2-box model would be similar in concept to previously developed $\mathrm{Na} / \mathrm{Cs}$ exchange models (Teppen and Miller, 2006, Van Loon and Glaus, 2008). In those cases, hydration energy alone was sufficient to suggest why Cs uptake is favored over Na uptake as a function of increasing compaction. In

A

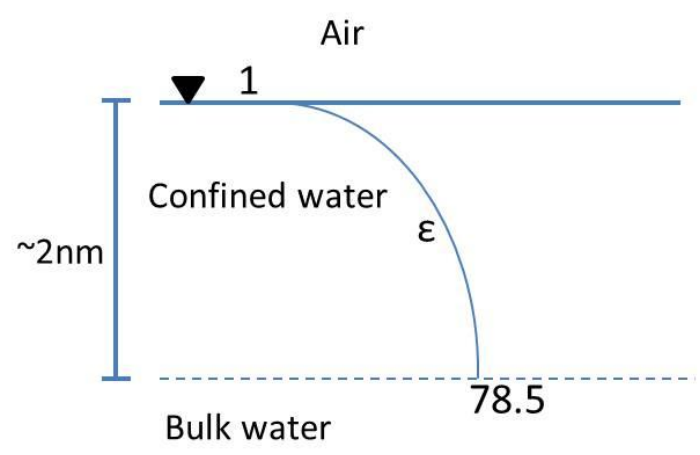

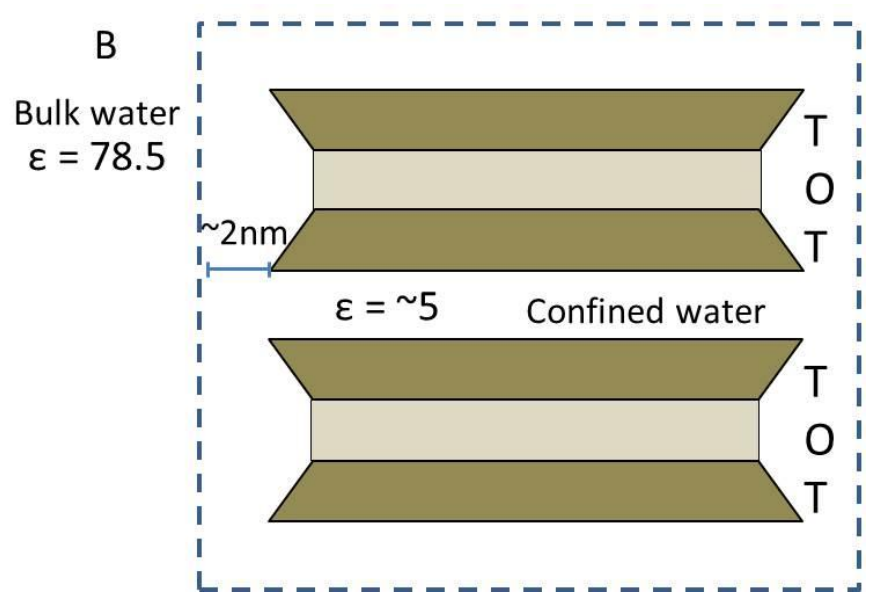

Figure 3- A- Conceptual model of the dielectric constant change near the air-water interface, B- 2-box model proposed here for clay minerals. $\mathrm{T}=$ tetrahedral layer, $\mathrm{O}=$ octahedral layer. 
this case, a similar conceptual model may still hold, but the variables of interest need to include: the polarizability of the anion, the formation constant of the ion pair, changes to the dielectric constant based on geometry and clay charge, as well as the hydration energies of the ions involved. Molecular simulations would be required to understand the ultimate driving force for iodide concentration near the clay surfaces.

It is difficult to extrapolate such results to more disposal relevant systems. Generally the ionic strength of clay pore waters is on the order of $0.1 \mathrm{M}$, and tend to be dominated by $\mathrm{NaCl}$, although $\mathrm{Ca}^{2+}$, $\mathrm{Mg}^{2+}, \mathrm{K}^{+}, \mathrm{SO}_{4}{ }^{2-}$, and $\mathrm{HCO}_{3}{ }^{-}$are also generally present. Given the variability between the iodide uptake in the different swamping electrolytes it is unclear if the behaviors observed would still occur in mixtures of those electrolytes. Also the aqueous iodide concentrations used here are likely much higher than what will be seen in the far field of a waste repository. It is not clear whether these interactions would still be observable at more relevant concentrations. Finally, if the proposed interpretation is correct, iodide uptake should be exacerbated in compacted systems where a larger proportion of the pore water is affected by the clay surfaces. The proposed interpretation may also help to explain the diffusion of anions at large dry densities $\left(>\sim 1600 \mathrm{~kg} / \mathrm{m}^{3}\right)$. At these very high densities there is a theoretical point where the clay double layers overlap, filling the pore space and excluding anions from diffusing. One hypothesis to explain anion diffusion above that critical dry density is non-uniform pore structure (Tournassat and Appelo, 2011). An alternative version is that some anions are diffusing as neutral ionpairs, and thus would not be affected by the charge domain in solution.

lodide interactions with clay minerals are so weak experimental attempts at understanding them are hampered by the fact that the error is generally larger than the $K_{D}$ value. The same was true here. Furthermore, the physical model described was arrived at by excluding other processes based on the data. Thus the model is proposed and not unambiguously confirmed. However, in this case, using a broad study of several clay minerals allowed for the observation of trends as a function of lattice substitution and clay structure. This in turn gave insight into a possible, generally unconsidered mechanism for direct iodide interaction with clays that does not violate current surface complexation/ion exchange models for clays. This relationship appears valid despite the variability in $\mathrm{pH}$ values for the different electrolyte systems, the chemical variability between the clays used and the general lack of clay purification. The iodide uptake mechanism appeared as an emergent property heavily related to structural charge and clay texture alone. However, the thermodynamic driver of iodide accumulation near clay surfaces is still vague. And, although the experimental data indicate that iodide can directly interact with clay minerals despite the negative charge, it also remains unclear what ultimately controls the slope of iodide uptake as a function of CEC. One possible explanation is that given the affinity of iodide for interlayer sites created by nanopore confinement (through ion pairing) and molecular polarization effects, the increase in the negative structural charge of clay plates tends to reduce the overall affinity for iodide uptake. Finally, the proposed mechanism does not invalidate any of the other potential mechanisms for iodide interaction with clays discussed in the Introduction. Several weak mechanisms may be needed to describe iodide interaction with various clay minerals in various geologic environments. 


\section{Acknowledgements}

Sandia National Laboratories is a multi-program laboratory managed and operated by Sandia Corporation, a wholly owned subsidiary of Lockheed Martin Corporation, for the U.S. Department of Energy's Nation Nuclear Security Administration under contract DE-AC04-94AL85000. This project was funded through the Used Fuel Disposition Campaign and through a Laboratory Directed Research and Development grant. Funding was also provided through Emporia State University start-up funds. The authors would like to thank Hernesto Tellez for help with analytical work.

\section{Supporting Information Available}

Plots showing the $K_{D}$ values as a function of BET surface area for all of the electrolyte compositions and concentrations are available in the supporting information.

\section{References}

Altmann, S. (2008) 'Geo'chemical research: A key building block for nuclear waste disposal safety cases', Journal of Contaminant Hydrology, 102(3-4), pp. 174-179.

Appelo, C. A. J., Van Loon, L. R. and Wersin, P. (2010) 'Multicomponent diffusion of a suite of tracers (HTO, Cl, Br, I, Na, Sr, Cs) in a single sample of Opalinus Clay', Geochimica Et Cosmochimica Acta, 74(4), pp. 1201-1219.

Baeyens, B. and Bradbury, M. (1997) 'A mechanistic description of Ni and Zn sorption on Namontmorillonite Part I: Titration and sorption measurements', Journal of Contaminant Hydrology, 27, pp. 199-222.

Bazer-Bachi, A. R., Tevisson, E., Descostes, M., Grenut, B., Meier, P., Simonnot, M.-O. and Sardin, M. (2006) 'Characterization of iodide retention on Callovo-Oxfordian argillites and its influence on iodide migration', Physics and Chemistry of the Earth, 31, pp. 517-522.

Bergaya, F., Theng, B. K. G. and Lagaly, G. (2006) Handbook of Clay Science. Amsterdam: Elsevier.

Borden, D. and Giese, R. F. (2001) 'BASELINE STUDIES OF THE CLAY MINERALS SOCIETY SOURCE CLAYS: CATION EXCHANGE CAPACITY MEASUREMENTS BY THE AMMONIA-ELECTRODE METHOD', Clays and Clay Minerals, 49(5), pp. 444-445.

Bradbury, M. H. and Baeyens, B. (1997) 'A mechanistic description of $\mathrm{Ni}$ and $\mathrm{Zn}$ sorption on Namontmorillonite Part II: modeling', Journal of Contaminant Hydrology, 27, pp. 223-248.

Brunauer, S., Emmett, P. H. and Teller, E. (1938) 'Adsorption of Gases in Multimolecular Layers', Journal of the American Chemical Society, 60(2), pp. 309-319.

Cases, J. M., Grillet, Y., Francois, M., Michot, L., Villieras, F. and Yvon, J. (1991) 'Evolution of the porous structure and surface area of palygorskite under vacuum thermal treatment', Clays and Clay Minerals, 39(2), pp. 191-201.

Charlet, L. and Tournassat, C. (2005) 'Fe(II)- $\mathrm{Na}$ (I)-Ca(II) Cation Exchange on Montmorillonite in Chloride Medium: Evidence for Preferential Clay Adsorption of Chloride - Metal Ion Pairs in Seawater', Aquatic Geochemistry, 11(2), pp. 115-137.

Claret, F., Lerouge, C., Laurioux, T., Bizi, M., Conte, T., Ghestem, J. P., Wille, G., Sato, T., Gaucher, E. C., Giffaut, E. and Tournassat, C. (2010) 'Natural iodine in a clay formation: Implications for iodine fate in geological disposals', Geochimica Et Cosmochimica Acta, 74(1), pp. 16-29.

Couture, R. A. and Seitz, M. G. (1983) 'Sorption of anions of iodine by iron oxides and kaolinite', Nuclear and Chemical Waste Management, 4, pp. 301-306.

Descostes, M., Blin, V., Bazer-Bachi, F., Meier, P., Grenut, B., Radwan, J., Schlegel, M. L., Buschaert, S., Coelho, D. and Tevissen, E. (2008) 'Diffusion of anionic species in Callovo-Oxfordian argillites and 
Oxfordian limestones (Meuse/Haute-Marne, France)', Applied Geochemistry, 23(4), pp. 655677.

Fuge, R. and Johnson, C. C. (1986) 'THE GEOCHEMISTRY OF IODINE - A REVIEW', Environmental Geochemistry and Health, 8(2), pp. 31-54.

Fuhrmann, M., Bajt, S. and Schoonen, M. A. A. (1998) 'Sorption of iodine on minerals investigated by Xray absorption near edge structure (XANES) and I-125 tracer sorption experiments', Applied Geochemistry, 13(2), pp. 127-141.

Fuoss, R. M. (1980) 'Conductimetric determination of thermodynamic pairing constants for symmetrical electrolytes', Proceedings of the National Academy of Sciences, 77(1), pp. 34-38.

Galan, E. (1996) 'Properties and applications of palygorskite-sepiolite clays', Clay Minerals, 31(4), pp. 443-453.

Gaucher, E., Robelin, C., Matray, J. M., Négrel, G., Gros, Y., Heitz, J. F., Vinsot, A., Rebours, H., Cassagnabère, A. and Bouchet, A. (2004) 'ANDRA underground research laboratory: interpretation of the mineralogical and geochemical data acquired in the Callovian-Oxfordian formation by investigative drilling', Physics and Chemistry of the Earth, Parts $A / B / C, 29(1)$, pp. 55-77.

Gaucher, E. C., Blanc, P., Bardot, F., Braibant, G., Buschaert, S., Crouzet, C., Gautier, A., Girard, J. P., Jacquot, E., Lassin, A., Negrel, G., Tournassat, C., Vinsot, A. and Altmann, S. (2006) 'Modelling the porewater chemistry of the Callovian-Oxfordian formation at a regional scale', Comptes Rendus Geoscience, 338(12-13), pp. 917-930.

Gillman, G. (1979) 'A proposed method for the measurement of exchange properties of highly weathered soils', Soil Research, 17(1), pp. 129-139.

Glaus, M. A., Muller, W. and Van Loon, L. R. (2008) 'Diffusion of iodide and iodate through Opalinus Clay: Monitoring of the redox state using an anion chromatogrpahic technique', Applied Geochemistry, 23, pp. 3612-3619.

Hiemstra, T. and Van Riemsdijk, W. H. (1991) 'Physical chemical interpretation of primary charging behaviour of metal (hydr) oxides', Colloids and Surfaces, 59(0), pp. 7-25.

$\mathrm{Hu}, \mathrm{Q}$. and Moran, J. E. (2005) 'Simultaneous analyses and applications of multiple fluorobenzoate and halide tracers in hydrologic studies', Hydrological Processes, 19, pp. 2671-2687.

Hu, Q., Zhao, P., Moran, J. E. and Seaman, J. C. (2005) 'Sorption and transport of iodine species in sediments from the Savannah River and Hanford Sites', Journal of Contaminant Hydrology, 78, pp. 185-205.

Jansson, M. and Eriksen, T. E. (2004) 'In situ anion diffusion experiments using radiotracers', Journal of Contaminant Hydrology, 68(3-4), pp. 183-192.

Jungwirth, P. and Tobias, D. J. (2001) 'Molecular Structure of Salt Solutions: A New View of the Interface with Implications for Heterogeneous Atmospheric Chemistry', The Journal of Physical Chemistry B, 105(43), pp. 10468-10472.

Kahr, G. and Madsen, F. T. (1995) 'Determination of the cation exchange capacity and the surface area of bentonite, illite and kaolinite by methylene blue adsorption', Applied Clay Science, 9(5), pp. 327-336.

Kaplan, D. I. (2003) 'Influence of surface charge of an Fe-oxide and an organic matter dominated soil on iodide and pertechnetate sorption', Radiochimica Acta, 91(3-2003), pp. 173-178.

Kaplan, D. I., Serne, R. J., Parker, K. E. and Kutnyakov, I. V. (2000) 'lodide Sorption to Subsurface Sediments and Illitic Materials', Environmental Science \& Technology, 34(3), pp. 399-405.

Kozaki, T., Inada, K., Sato, S. and Ohashi, H. (2001) 'Diffusion mechanism of chloride ions in sodium montmorillonite', Journal of Contaminant Hydrology, 47(2-4), pp. 159-170.

Laird, D. A. (2006) 'Influence of layer charge on swelling of smectites', Applied Clay Science, 34(1-4), pp. 74-87. 
Li, D., Kaplan, D. I., Knox, A. S., Crapse, K. P. and Diprete, D. P. (2014) 'Aqueous 99Tc, 129I and 137Cs removal from contaminated groundwater and sediments using highly effective low-cost sorbents', Journal of Environmental Radioactivity, 136(0), pp. 56-63.

Lima, E. R. A., Bostrom, M., Horinek, D., Biscaia, E. C., Kunz, W. and Tavares, F. W. (2008) 'Co-lon and Ion Competition Effects: Ion Distributions Close to a Hydrophobic Solid Surface in Mixed Electrolyte Solutions', Langmuir, 24(8), pp. 3944-3948.

Mallants, D., Marivoet, J. and Sillen, X. (2001) 'Performance assessment of the disposal of vitrified highlevel waste in a clay layer', Journal of Nuclear Materials, 298(1-2), pp. 125-135.

Manciu, M. and Ruckenstein, E. (2005) 'On the Interactions of Ions with the Air/Water Interface', Langmuir, 21(24), pp. 11312-11319.

Mattigod, S. V., Frampton, J. A. and Lim, C. H. (1985) 'Effect of ion-pair formation on boron adsorption by kaolinite', Clays and Clay Minerals, 33(5), pp. 433-437.

Miller, A. W. and Wang, Y. (2012) 'Radionuclide Interaction with Clays in Dilute and Heavily Compacted Systems: A Critical Review', Environmental Science \& Technology, 46(4), pp. 1981-1994.

Montavon, G., Sabatié-Gogova, A., Ribet, S., Bailly, C., Bessaguet, N., Durce, D., Giffaut, E., Landesman, C. and Grambow, B. (2014) 'Retention of iodide by the Callovo-Oxfordian formation: An experimental study', Applied Clay Science, 87(0), pp. 142-149.

Ockwig, N. W., Greathouse, J. A., Durkin, J. S., Cygan, R. T., Daemen, L. L. and Nenoff, T. M. (2009) 'Nanoconfined Water in Magnesium-Rich 2:1 Phyllosilicates', Journal of the American Chemical Society, 131(23), pp. 8155-8162.

Savoye, S., Frasca, B., Grenut, B. and Fayette, A. (2012) 'How mobile is iodide in the Callovo-Oxfordian claystones under experimental conditions close to the in situ ones?', Journal of Contaminant Hydrology, 142-143(0), pp. 82-92.

Senapati, S. and Chandra, A. (2001) 'Dielectric Constant of Water Confined in a Nanocavity', The Journal of Physical Chemistry B, 105(22), pp. 5106-5109.

Shock, E. L. and Helgeson, H. C. (1988) 'Calculation of the thermodynamic and transport properties of aqueous species at high pressures and temperatures: Correlation algorithms for ionic species and equation of state predictions to $5 \mathrm{~kb}$ and $1000^{\circ} \mathrm{C}^{\prime}$, Geochimica Et Cosmochimica Acta, 52(8), pp. 2009-2036.

Sposito, G. (1991) 'Effect of Chloride Ions on Sodium-Calcium and Sodium-Magnesium Exchange on Montmorillonite', Soil Sci. Soc. Am. J., 55(4), pp. 965-967.

Sposito, G., Holtzclaw, K. M., Charlet, L., Jouany, C. and Page, A. L. (1983) 'Sodium-Calcium and SodiumMagnesium Exchange on Wyoming Bentonite in Perchlorate and Chloride Background Ionic Media', Soil Sci. Soc. Am. J., 47(1), pp. 51-56.

Teppen, B. J. and Miller, D. M. (2006) 'Hydration energy determines isovalent cation exchange selectivity by clay minerals', Soil Science Society of America Journal, 70(1), pp. 31-40.

Tournassat, C. and Appelo, C. A. J. (2011) 'Modelling approaches for anion-exclusion in compacted Nabentonite', Geochimica Et Cosmochimica Acta, 75(13), pp. 3698-3710.

Tournassat, C., Gaucher, E. C., Fattahi, M. and Grambow, B. (2007) 'On the mobility and potential retention of iodine in the Callovian-Oxfordian formation', Physics and Chemistry of the Earth, 32(8-14), pp. 539-551.

Van Loon, L. R. and Glaus, M. A. (2008) 'Mechancial Compaction of Smectite Clays Increases Ion Exchange Selectivity for Cesium', Environmental Science \& Technology, 42(5), pp. 1600-1604.

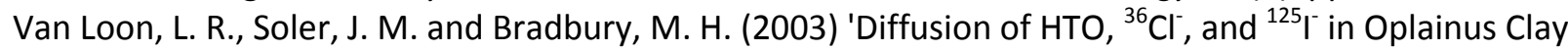
samples from Mont Terri Effect of confining pressure', Journal of Contaminant Hydrology, 61, pp. 73-83.

Whitehead, D. C. (1984) 'The Distribution and Transformations of lodine in the Environment', Environment International, 10, pp. 321-339. 
Wittebroodt, C., Savoye, S. and Gouze, P. (2008) 'Influence of initial iodide concentration on the iodide uptake by the argillite of Tournemire', Physics and Chemistry of the Earth, Parts $A / B / C, 33(14-$ 16), pp. 943-948.

Yeh, I. C. and Berkowitz, M. L. (1999) 'Dielectric constant of water at high electric fields: Molecular dynamics study', Journal of Chemical Physics, 110(16), pp. 7935-7942. 